\title{
E-Leaning and the Needs of People with Language \\ Problems in Nigeria
}

\author{
Martha Chidinma Egenti*
}

\begin{abstract}
Different Education Reform Acts and Policies have been promulgated in Nigeria. These include the National Policy on education (FRN) as revised in 1998 and 2004, the national policy for Information Technology (IT) of 2001, Federal Ministry of Education (FME, 2004) and the education reform act of 2007etc.These acts/policies show that the Nigerian education sector is abreast of modern technology development. However, this paper examines the NITDA act of 2007 with a view to ascertaining how it has catered for the e-learning needs of those with language problems. The examination reveals that people with language problems have not been taken into consideration. On the basis of this analysis, the paper not only recommends the recognition of such people but also indicates the means of catering for their e-learning needs. http://dx.doi.org/10.4314/ujah.v13i1.3
\end{abstract}

\section{Introduction}

The concept of 'global village' was envisioned by McLuhan since 1964. In pointing out the medium for attaining this global village, Inglis, Ling, and Joosten (2002), Laurillard (2002), Evans and Nation (2000) assert that e-learning and the Internet are the ideal medium to create a global village.

With the advent of ICT, information is easily stored, shared and retrieved locally, nationally and internationally. ICT affords a person the opportunity to capture, store and distribute information and resources of all types and forms regardless of domain. This can be done through the internet which encompasses concepts such as 'global village' and 'econcepts'. Following from this trend, no government of any country, especially developing countries, wants to be left 
behind with regard to incorporating this trend into all sectors of her economy in order to meet modern technological advancement. Nigeria is currently doing something to accommodate this new trend in every sector of her economy namely: finance, agriculture, religion, commerce, health, engineering, education and even governance. Hence, today we have concepts such as, ePayment, eBusiness, eLibrary, eLearning and even eGovernance which have emerged as a viable means to addressing development issues and challenges.

Due to the growing popularity of e-Learning in all areas and walks of life and at different levels of education and training, this paper tries to examine the ICT policies of government especially with regard to education to see if the people with language problems are carried along as "the concept of McLuhan's "global village" seems to hold true by the prophecy of Hanna when she says that the global village "is about to come to life for every person on the planet" (p.8) (Emphasis is mine). Preceding this examination, the following issues are discussed as follows: the concept of e-learning and the different areas of e-learning and training, language problems and the different types and the type of errors that are associated with them, the promotion of ICT and e-learning by the efforts being made by individuals and the ICT policies by the Federal Government towards the promotion of ICT and elearning using the implementing platform called NITDA National Information Technology Development Agency. The last section of this paper is conclusion.

\section{The Concept of E-Learning and other e-Activities}

The 'e' in e-Learning simply means "electronic". It is a relatively new phenomenon that relates to the use of electronic media. However, there seems to be no agreement with regard to the variety of its spelling. The concept is viewed from different perspectives by different scholars and organizations 
depending on how it is used. We shall in this work adopt the elearning spelling for the purpose of consistency.

E-learning is the use of the Internet technologies to create and deliver a rich learning environment that includes a broad array of instruction and information resources and solutions, the goal of which is to enhance individuals and organizations (Resenberg, 2006). It has also been defined by the American Society for Training and Development (ASTD) as "a broad set of applications and processes which includes web-based learning, computer-based learning, virtual classroom and digital which is delivered through the internet, intranet, audio and videotape, satellite broadcast, interactive TV and CD-ROM". On the other hand, Guri-Rosenblit (2005) holds that all forms of learning through ICT are referred to as e-learning. She draws a clear distinction between e-learning and distance education. According to her, e-Learning and distance education are not the same thing. They do have common characteristics and similarities in some cases but are not identical. While 'e-Learning' is the use of electronic media for a variety of learning purposes that range from add-on functions in conventional classrooms to full substitution for the face-to-face meetings by online encounters, distance education is not campus-based rather it is aimed at students from dispersed locations who are physically distant from their teacher and teaching institution (Gurit-Rosenblit, 1999).

The Open and Distance Learning Quality Council (ODLQC) of the United Kingdom defines e-Learning as "the effective learning process created by combining digitally delivered content with (learning) support and services" (Waller $\&$ Wilson, 2001). The concept of e-learning and distance learning has the Internet as their meeting point. They are usually described and differentiated in terms of time and distance. However, Naidu, not only defines e-Learning, he also explains the mode of teaching and learning involved in elearning. According to him: 
The term e-learning comprises a lot more than online learning, virtual learning, distributed learning, networked or web-based learning. As the letter "e" in e-learning stands for the word "electronic", e-learning would incorporate all educational activities that are carried out by individuals or groups working online or offline, and synchronously or asynchronously via networked or standalone computers and other electronic devices (1).

He explains the various modalities of e-learning in terms of individualized self-paced e-learning online or offline and group-based e-learning synchronously or asynchronously. The former refers to learners accessing learning resources such as database or course content online through the Internet or Intranet or working alone offline i.e while not connected to the Internet but using the computed-assisted learning packing stored in a Compact Disk (CD) or Digital Video Disk (DVD). The latter on the other hand, involves group of learners working at the same time (synchronous) via an Intranet or the Internet using real time chats or audio-video conferencing or at different times (asynchronous) which involves discussion of topic through email exchange and text-based conferencing.

Following from the above, e-learning when put succinctly, involves all forms of learning, teaching and training that are facilitated by a computer-based worldwide information network usually referred to as the Internet regardless of time or distance. The next section discusses the nature of language problems and how it can interfere with learning, communication and cognition. 


\section{The Nature of Language Problems}

Feedback is one of the important elements to show effective communication. Thus, understanding language precedes expression and use. This is to say that language can be receptive and expressive. This explains why speech and language exist together. In the same vein, speech and language disorders exist together or by themselves. People with language problems usually commit errors at the different levels of language production. The errors lead to serious education consequences. We shall look at these errors in this section.

Put simply, language problems refer to inability of a person to express, formulate and comprehend a message. It varies according to types and degree of severity and are called several names in the literature as stated by American SpeechLanguage Hearing Association. These include: language disorder, specific language disability, language disability, language delay, language deviance, language impairment, language difficulties and language difference etc. The concept of speech and language problems has often been used interchangeably but they mean different things and they also have their specifics. Osuorji draws a clear distinction between speech and language disorders. $\mathrm{He}$ asserts that the classification is very necessary for the purpose of appropriate identification and assessment. For him, speech difficulties refer to problems with perception or the articulation of speech sounds, while language difficulties refer to a range of problems that can interfere with communication and cognition. In essence, speech disorder refers to problem in sending or delivering message. It is associated with articulation of speech sounds, fluency and voice whereas a language disorder is impaired comprehension or use of spoken written and other symbols system. Thus, language disorder reflects problems in receiving, understanding and formulating a message.

Language problems can occur in isolation or in combination with other disabilities. They can be mild or severe 
and it falls under two categories namely receptive and expressive. Children who have trouble understanding what others say (receptive), and those that have difficulty in sharing their thoughts (expressive) may have a language problem (http://www.nidcd.nih.gov/health/voice/pages/speechandlangu age.asp). These two categories can be analyzed from the different levels of linguistics, namely, phonology, morphology, syntax, semantics and pragmatics.

There are five different dimensions that work together in the production of language. Children can have problems with any of the dimensions either in isolation or in combination. Errors that are usually associated with various levels of linguistics are explained by Thumbull, Tumbull III, Shank, and Leal as follows:

(1) Phonological errors (formerly called articulation error) whereby a sound can be substituted; omitted or added.

(2) In morphology, errors are usually associated with number and tense of verbs, e.g., "the dogs barks"; use of case and gender for personal pronoun, e.g, "thems my shoes"; difficulty in understanding adjective comparison and use of derived nouns or adverbs such as slowly from slow, banker from bank, etc.

(3) Syntactic errors are usually found in word order. Peterson outlines the errors as follows:

- Absence of syntactic structure in speech

- Limited structures for a given age or developmental level e.g a 3 year old child using one word utterances.

- Incorrect structures, such as misuse of negatives

- Omission of structures where they should be used as in omission of preposition or other functional parts of speech.

(4) Semantic errors are obvious in the use of words with double meanings, abstract terms, synonyms and idioms; difficulty in expressing the relationship with words in sentences that involve the use of conjunction and between 
clauses within a sentence; and problems in words/concepts that express time and space, cause and effect, inclusion and exclusion.

(5) Pragmatic errors include difficulty in taking turns in conversion, giving appropriate answers or responding to questions; difficulty in understanding a joke, a funny and a serious situation; and poor code switching, i.e., difficulty in relating appropriately in terms of use of language to different persons such as his father, his friend, grandmother, etc. His verbal and nonverbal form of communicating is inappropriately varied in situations.

Having discussed errors at the different linguistic levels a person with language problems may make, it should however be noted that the severity of the language problems determine the extent of their effects on the language systems of a particular language. From the above, a person is considered as having a language problem if his/her sentence structure and vocabulary are sufficiently different when compared with others of his/her age or if the person's speech deviates from the usual way in which sounds are produced. The next section discusses the efforts at promoting ICT and e-learning by the government.

\section{Promotion of ICT and E-Learning}

It will be right to say that almost all the sectors in the country have adopted ICT in their operations. The present and past governments have endeavored to ensure the use of ICT in the different government parastatals. Efforts have also been made by different scholars to develop Nigerian keyboard, Ajayi notes that most of these efforts have been met with lack of funding and support by the Federal Government. This explains why Uchechukwu decries the lack of implementation with regard to ICT policies. Nevertheless, all these efforts are geared towards driving the nation and its economy to a 
knowledge-based one. This also explains why the Federal Government set up an agency whose responsibility is to take care of the ICT needs of the country. This agency is popularly known by its acronym NITDA - National Information Technology Development Agency. It was approved by the Federal Executive Council (FEC) in 2001 to implement the Information Technology (IT) polices and was passed into law in 2007. According to the NITDA Act 2007, the mandate and/or functions of the Agency are, among other things, to:

Create a frame work for the planning, research, development, standardization, application, coordination, monitoring, evaluation and regulation of Information Technology practices, activities and systems;

- Develop guidelines for electronic governance, networking of public and private sector establishments; and for the standardization and certification of information technology systems in Nigeria;

- $\quad$ Develop guidelines for electronic governance and monitor the use of electronic data interchange and other forms of electronic communication transactions as an alternative to paper-based methods in government, commerce, education, the private and public sectors, labour, and other fields, where the use of electronic communication may improve the exchange of data and information.

- Render advisory services in all information technology matters to the public and private sectors and create incentives to promote the use of information technology in all spheres of life in Nigeria including the setting up of information technology parks.

- Determine critical areas in Information Technology requiring research intervention and Development in those areas. 
Advice the Government on ways of promoting the development of information technology in Nigeria including introducing appropriate information technology legislations, to enhance national security and vibrancy of the industry.

NITDA since its inception has made remarkable and appreciable achievements in terms of increasing the number of the Internet users, although, there are a number of ICT challenges which include among others, inadequate infrastructure, security and lack of local content. The implementation of eApplication refers to the application of ICT in every sector of human life: governance (eGovernment), Education (eLearning), Health (eHealth), Agriculture (eAgriculture) e.t.c. This has also been met with major challenges such as lack of requisite infrastructure, appropriate legal framework and affordable/reliable services.

In spite of the immense progress made so far, there is little addressing the needs of people with language problems. This may have something to do with the NITDA law. We evidence this in the next section.

\section{Implications of the NITDA Law for E-Learning}

In as much as NITDA is improving in the aspect of humancapacity building as noted by Adekoya, it has among others achievements established Internet Exchange Points (IXP) to crash internet cost and provided internet access to some higher institutions. Also, it has awarded scholarships to students undertaking IT related courses in $\mathrm{MA} / \mathrm{PhD}$ and succeeded in training of lecturers in selected universities in Nigeria; one in each state. All these achievements notwithstanding, there is need for the agency to reach out and permeate the different levels in the educational system as well as strengthen the intervention programmes on ICTs capacity building to include 
teaching staff and students at the lower level of education system.

An additional point is that since the NITDA is an implementing body of the ICT Policy, it already operates within the confines of the objectives of the IT policy whose objective among others is: to integrate IT in the mainstream of education and training, to empower youths with ICT skills to prepare them for competitiveness in a global environment and to establish multifaceted ICT institutions as centre for excellence on ICT. The policy document of 2001 which NITDA is to implement does not recognize in its components the need to use the computer or ICT to provide access for the benefits and education of people with disability. This no doubt has restricted its mandate. Yusuf in his analysis of the Nigerian national policy for information technology (FRN 2001) notes that the policy was inadequate for positive impact on the Nigerian education system because its framework is market driven which explains why little emphasis on the integration of ICT in instruction is laid. What this suggests is that the ICT needs of people with language disability should be incorporated in the national policy of 2001 so as to enable them have access to quality education. Some of these ICT needs are highlighted in the next section.

\section{Needs of People with Language Problems and How They Can Be Met}

People with language problems have different language needs in speech production or comprehension. A person may be deficient in only speech or language or may have other disabilities which could be as a result of brain lesion or the like. But these basic needs can be met through identification, assessment and the use of computer-assisted technology devices. Such assistive devices assist learning in the classroom. The devices are usually computers or specialized equipment that meets the individual needs of students. They 
range from simple pictures and symbols on paper to electronic switches or computer-generated speech-output devices which can be used by people who have a problem in producing language whether in speech or writing and also by those who have difficulty in understanding language. These assistive technologies can be classified under the following:

\section{Language Production Problems and Possible Assistive ICT Solutions}

People who have difficulty in producing language can improve in learning, academic performance and communication by using the following assistive technologies (AT) which is also a part of Augmentative and Alternative Communicative (AAC) Device. This device includes electronic and computer-based technologies as well as non-technological techniques. They are used by people who do not speak or have trouble being understood. This device can assist people who are also affected by conditions such as autism, cerebral palsy, dysarthria and strokes. Some of these AAC tool include:

1. Automatic Speech recognition system, a speech-to-text device. A speaker-dependent recognizer can be used in training people with speech impairment to read text from screen so that the software will recognize their voices. This training should be carried out especially in relation to the individual's needs and strength and in conjunction with other output voice communication aids.

2. Speech review utilities

3. Speech synthesizers

4. Adaptive ICT includes keyboards with colourful keys for persons with learning disabilities, voice recognition and the accessible web accessibility option initiative of the W3 Consortium designed to provide web access for people with disability (Yusuf and Yusuf, 2009) 


\section{Language Comprehension Problems and Possible Assistive ICT Solutions}

People who have hearing impairment also have their ICT needs. For such people with hearing impairment, Stover and Pendegraft (94) identify and re-emphasize the need for using the computed-aided notetaking/transcription technologies (CAN) especially in situation where the ASL (American Sign Language) becomes difficult when used in some science related subject like physics, chemistry etc. Here, the CAN technologies "provide a feasible and potentially more accurate alternative to ASL in such situations" (p.97). According to them, the CAN is also an indispensible assistive tool for people with hearing-impairments and has been in existence for more than a decade (p.96). There are also adaptive communication systems such as the Telephone devices for the deaf (TDDs) now called the TTs (Text telephones) and sequential software for language intervention. On the other hand, there are also some assistive technologies for the blind and visually impaired. These assistive technologies range from screen readers to screen magnifier, scan/read systems, potable notetakers, video magnifiers and digital book readers as listed in (www.assist.vt.edu/atServices/toolsAndDevices). These computer-aided programs help to stimulate, reinforce and capture interest and attention of children and youth which enables effective learning and makes it easier and more fun.

\section{Conclusion and Recommendations}

The full use of technological advancements, particularly as it relates to people with language problem is still not yet attained in Nigerian special school system. It has not yet recorded any success story even in some sectors. This paper has attempted to bring to limelight the need for NITDA to incorporate the ICT needs of people with language problems in their services so as to provide for better education of these people. The academic, social and emotional impact it will create cannot be 
overemphasized. It will not only bridge the yawning discrepancies that exist between people with language problems and their counterparts who do not have language problems but also position them for greater performance and improvement. It is only after this has been done that we can talk of good governance which is characterized by eight major characteristics as stated by Unescap: it is participatory, consensus oriented, accountable, transparent, responsive, effective and efficient, equitable and inclusive and follows the rule of law. An additional fact is that every citizen of any country has the right to the benefits of information and technology. People with language problems are also citizens who have their own ICT needs which should be incorporated in the ICT Policies. It is for this reason that the paper recommends that:

- ICT computer-assisted devices for people with language problems should be given utmost priority by the Government both in the primary and post primary education with adequate funding and support. This should be done in collaboration with the public and private sectors.

- The ICT needs of people with language problem should be clearly stated in government policies.

- Teachers should be trained and empowered in the use of Internet so that they can improve in their 'teaching style'. For instance, people who are mute need a generous use of demonstrations and visual aids such as projector in teaching and training them for effective learning. Also, a person with language problems even if they are not in a special education setting should be given related services (i.e. services that will help to remediate, e.g., speech difficulties) and appropriate education. This could be in form of speech-language skill training/workshop because 
most people who have speech-language problems are enrolled in regular schools.

- Speech-Language therapists, special education experts and computer assistive technology professionals who are knowledgeable and trained should be consulted and employed on the type of assistive technology products that can be easily installed, set up and used by people with language difficulties at different levels of education.

- This paper notes that e-learning can only be viable and realistic with the basic infrastructure and stable electricity. This is in support of Bates' assertion that 'e-learning is heavily dependent on appropriate technological infrastructure already being in place for commerce and government reasons. Stable electricity and reliable and moderately priced Internet access is a necessary condition for e-learning" (113).

This paper concludes that the government has an enormous responsibility in ensuring that the ICT needs of the governed especially those of the people with language problems are integrated in the ICT policy of the country and adequately addressed.

* Martha Chidinma Egenti lectures in the Department of Linguistics, Nnamdi Azikiwe University,Awka. 


\section{References}

Adekoya A. NITDA Certifies Local Original Equipment Manufacturers (OEMS) for Government Patronage. Retrieved from http://www.nitda.gov.ng/index.php/legaland-regulatory/national-it-policyNITDA certifies local OEMs for govt patronage. Vanguard Media, $3^{\text {rd }}$ September, 2012.

Ajayi, G. O. NITDA and ICT in Nigeria Retrieved on 10/4/12, http://ejd.org/meeting2003/ictp/paper/Ajayi, 2003.

American Society for Training and Development (ASTD). Retrieved on April 11, 2012. www.about.elearning.com/definition-of-e-learning and www.webopedia.com/TERM/e-learning.html

American Speech-Language-Hearing Association. Preferred practice patterns for the profession of speech-language pathology. Retrieved on April 10, 2012.http://www.asha.org/NR/rdonlyres/C589BA8F5931-48AA-8E02-59CF989DC01F/0/v1PPPSLP.pdf. 2004.

Assisted Technology Tools and Devices. Retrieved from www.assist.vt.edu/atServices/toolsAndDevices/index on $22 / 6 / 12$

Bates, A. W. National Strategies for E-learning in Postsecondary Education and Training. Paris: International Institute for Educational Planning, UNESCO. 2001.

Brown, B. L. Web-based-training. Report No. EDO-CE-00218. Washington, DC.: Office of Educational Research and Improvements. 2000. Retrieved on 16/4/12 from http://140.127.40.36/ttp/studentscollectionandwork/93CA $\mathrm{L} / \mathrm{m} 9253312 / 0406130831 / 5420293$. 
Evans T. and Nation D. (eds). Changing University Teaching. London: Kogan Page, 2000.

Federal Republic of Nigeria (FRN) National policy on education $\left(4^{\text {th }}\right.$ ed.). Lagos: NERDC press 2004

Federal Ministry of Education (FME). Report on national policy on computer education. Lagos: Author, 1998.

Federal Minisry of Educatin (FME). Education Reform Act. Arrangement of parts (Education Sector Reform Bills). Abuja: Author.

Guri-Rosenblit, S. 'Distance Education' and 'E-Learning': Not the Same Thing. Higher Education, 2005, 4, 49: 467-493. Retrieved April 3, 2012 from http://www.jstor.org/stable/25068081.

Guri-Rosenblit, S. Distance and Campus Universities: Tensions and Interactions - A Comparative Study of Five Countries. Oxford: Pergamon Press \& The international Association of Universities. 1999.

Hanna, D. Higher Education in an Era of Digital Competition. Atwood: Madison. 2000.

Inglis, A., Ling P., and Joosten V. Delivering Digitally. London: Kogan Page. 2002.

Laurillard, D. Rethinking University Teaching. London: Routledge Falmer, 2002.

Loh, S. C. A Handbook of E-Learning: Two Reviewers Comment. The SAGE Handbook of E-Learning Research by Richard Andrews \& Caroline Haythornthwaite. Educational Researcher, 2007, 9, 36: 573-578. Retrieved on April 3, 2012 from www.jstor.org/stable/30137943. 
Naidu, S. E-learning: A Guidebook of Principles, Procedures and Practices. Commonwealth of learning. Commonwealth Educational Media Centre for Asia (CEMCA) New Delhi. 2006, (2 ${ }^{\text {nd }}$ ed.).

Osei, T. A. Survey Of Ict And Education In Africa: Nigeria Country Report Nigeria -1, ICT for Education in Nigeria. June 2007, Retrieved on April 10, 2012 from www.infodev.org.

Osuorji, P.I. Classification of Concepts for Appropriate Identification and Assessment: The Case of Speech and Language Disorders. In Shirley Yul-Ifode and Rotimi Badejo (ed.) Readings on Child Language and Communication Disorders in Nigeria. Port Harcourt: University of Port Harcourt Press, 978 978-4833226-9-4, 2008:281-290.

Peterson, N. Early intervention for handicapped and at-risk children. Denver: Love. 1987.

Resenberg, M. J. Beyond E-learning. John Wiley \% Sons, Inc: Pfeiffer, 2006.

Stover, Dana L. and Pendegraft Norman. Revisiting ComputerAided Notetaking: Technological Assistive Devices for Hearing-Impaired Students. Taylor \& Francis, the Clearing House, 2005, 79, 2: 94-97. Retrieved on June 18, 2012. http://www.jstor.org/stable/30182118.

The Ministerial Committee on ICT Policy Harmonization. National Information Communication Technology Policy Draft. Retrieved on April 10, 2012. www.tech/oy.com/wp content/uploads/2012/01/National_ICT_poliicy_Draft_09 0112. January 9, 2012. 
Turnbull ,A. P., Turnbull III, R. H., Shank M., and Leal D. Exceptional Lives: Special Education in Today's Schools. Prentice Hall, New Jersey. USA. 1995.

Uchechukwu, C. The Igbo Language and Computer Linguistics: problems and prospects. Proceedings of the Lesser Used Languages and Computer Linguistics Conference. Lesser used Languages Computer Linguistics (LULCL) $27^{\text {th }}-28^{\text {th }}$ Oct 2005. Isabella T. (Ed.), Bolzano, 2006.

UNESCAP. What is Good Governance? Retrieved June 19, 2012 from www.unescap.org/pdd/prs/governance.

Waller, V., and Willilson, J. A definition for e-learning (Electronic version). Open and Distance Learning Quality Council. Newsletter. Retrieved April 11, 2012, from http://www.odlqc.org.uk/n19-e.htm.

Yusuf M.O. and Yusuf H. T. Educational reforms in Nigeria: The potentials of information and communication technology (ICT). Educational Research and Review. 4 (5), 222-230. May 2009.Retrieved April 11, 2012 from http://www.academicjournals.org/ERR.

Yusuf M. O. Information and communication technology (ICT) and education: Analyzing the Nigerian national policy for information technology. Int.Educ. J. 6(3): 316321, ehlt.flinders.edu.au/education/iej/articles/v6n3/v6n3. 3rd September, 2012. 